\title{
Cranial Occipital Meningocoele in a Buffalo Calf
}

\author{
Sayyed Aun Muhammad ${ }^{1 *}$, Abdul Shakoor ${ }^{1}$, Dilshad Rashid ${ }^{2}$ and Hafiz Ishfaq Ahmad ${ }^{3}$ \\ ${ }^{1}$ College of Veterinary and Animal Sciences, Jhang, sub-campus -University of Veterinary and Animal Science, \\ Lahore-Pakistan \\ ${ }^{2}$ Para-veterinary institution, Karor, University of Veterinary and Animal Sciences, Lahore-Pakistan \\ ${ }^{3}$ Department of Animal Breeding and Genetics, University of Veterinary and Animal Sciences, Lahore-Pakistan \\ *For Correspondence: Email: aunmuhammad@uvas.edu.pk,draunmuhammad@gmail.com \\ Received 05 October 2020; Accepted 23 November 2020; Published 10 January 2021
}

\begin{abstract}
The report presents a case of rear congenital defects of occipital meningocoele in male buffalo calf of Neeli-Ravi breed. A soft fluctuating, fluid filled swelling was observed in the occipital region of skull. On the base of grass clinical examination and ultrasound examination, the case was diagnosed as occipital meningocoele and was recommended for surgical treatment under general anesthesia. An elliptical skin incision was made at the base of the swelling involving the skin. Fluid filled meningeal membranes were identified protruding out from the defect site. About one litter accumulated fluid in the sac was drained. The meninges close to the defect were resected and remaining part of meninges were sutured to close the defect. The animal got an uneventful recovery after 15 days of post-operative care. (C) 2021 Friends Science Publishers
\end{abstract}

Keywords: Meningocoele; Neeli-Ravi; Surgical intervention; Meningeal membranes

\section{Introduction}

Cranial Meningocoele is a congenital defect in which the fluid filled meningeal membranes get herniated from the defect to form an extra-cranial sac (Leipold 1993). This defect has been reported in various domestic animals, especially in cow calves (William et al. 2011; Ayhan et al. 2013) and kids (Laiju et al. 2012). The defect may be due to incomplete ossification of skull bones at frontal and occipital regions forming an opening of variable sizes through which the meningeal membranes can pass out (Oliver et al. 1987). This condition has been successfully treated surgically in kids and cow calves (William et al. 2011; Laiju et al. 2012; Ayhan et al. 2013). Only one case of cranial meningocoele has been (Ayyappan et al. 1996). The present report represents a novel case of congenital Meningocoele reported in buffalo calf occupying the frontal region of skull and was not treated surgically located at occipital region in a buffalo calf of Neeli-Ravi Breed and was treated successfully by surgical intervention.

\section{Materials and Methods}

\section{Case history and clinical observations}

A 22-days old male buffalo calf of Neeli -Ravi breed was examined under field condition with complaint of a large swelling present caudal to cranium (occipital region of skull) since birth. The swelling was soft, painless, fluctuating and having uniform consistency. The swelling had a total base circumference of $11 \mathrm{~cm}$ occupying the dorsal surface of atlanto-occipital area. The sac was hanging towards the right side of neck. The calf was of $47 \mathrm{~kg} \mathrm{~b}$. wt. The dam of the calf has been vaccinated annually against Foot and Mouth disease and Hemorrhagic septicemia disease. The calf was alert but had weak milk suckling response along with slight in-coordination during walking. No other congenital defect was found in the body of buffalo calf. Aseptic needle exploration of swelling yielded colorless watery fluid resembling the cerebrospinal fluid. By ultrasound examination, anechoic fluid was observed along with some hypo echoic area. On the basis of the clinical findings and ultrasound examination, the calf was tentatively declared as case of cranial meningocoele and was recommended for surgical treatment.

\section{Surgical treatment}

Fronto-occipital region was prepared aseptically after having shoved the hairs closely and scrubbing area with Pyodin scrub (Fig. 1). The calf was sedated with Intramuscular injection of Xylazine $\mathrm{HCl}$ (Inj. Xylaz, Farvet Lab. The Netherland) @ $0.01 \mathrm{mg} / \mathrm{kg} \mathrm{b}$. wt. and was placed in lateral recumbency. Injection Lingnocain was infiltrated at the base of sac to local numbness. An elliptical skin incision was made and the skin was separated from the underlying meningocoele sac (Fig. 2). Fluid filled meningeal membranes were identified protruding out from 


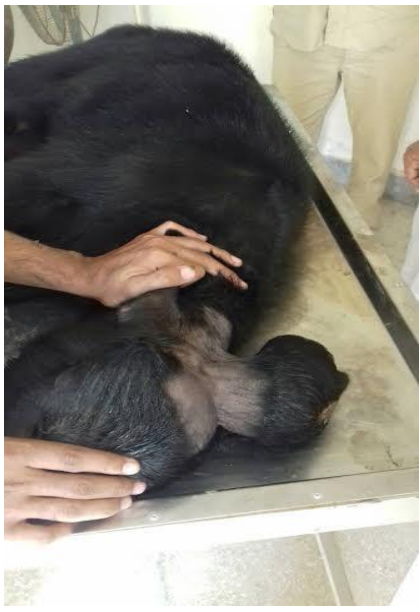

Fig. 1: Congenital swelling at the occipital region of skull

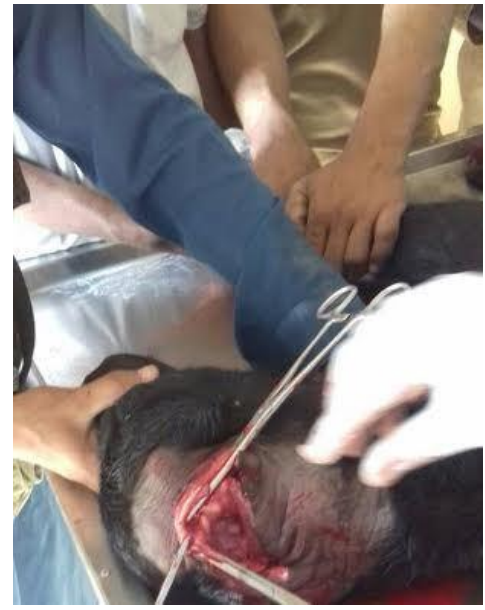

Fig. 2: Neuronal tube defect of $2 \mathrm{~cm}$ at the defective site

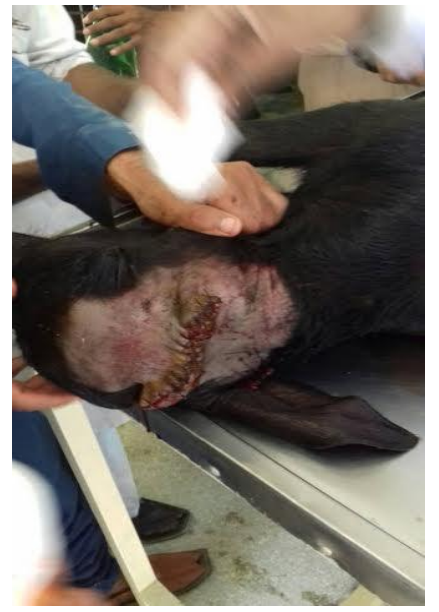

Fig. 3: Suturing of skin with simple interrupted suturing pattern the defect site. About one litter accumulated fluid in the sac was drained. The meninges close to the defect were resected. The size of defect was about $2 \mathrm{~cm}$ (Fig. 2). This defective site was sutured by suturing the overlying edges of resected tissue by simple continuous suturing pattern with Vicryl (Ethicon Vicryl suture 1-0). The skin edges were approximated by applying simple interrupted suture with braided silk (1 no. size) (Fig. 3). As a post-operative management, Injection Streptopenicillin $1 \mathrm{gm}$ was used I/M for five days and Injection Meloxicam (Inj. Diclostar, Star Lab. Pakistan) was used @ $0.2 \mathrm{mg} / \mathrm{kg} \mathrm{b}$. wt. sub-cut for 3 days. There was gradual improvement in the milk suckling response and animal recovered completely in 15 days.

\section{Results}

An elliptical incisional approach of surgery was used to explore and correct the neuronal tube defect and herniation of meningeal membrane. After 15 days' post-operative management of surgical wound the animal got recovery with no re-occurrence of meningeal membranes herniation and without any post-surgical complication. There was a gradual improvement in the milk suckling response.

\section{Discussion}

Meningocoele is a congenital defect of neuronal tube in which the neuronal tube is unable to fuse completely resulting in herniation of meningeal membrane. This defect is present at birth and may be found on different part of cranium especially the medial side of frontal bone (Maxie and Youssef 2007). In the present case, the herination of meningies was found on the occipital region. One case of meningocoele in buffalo calf has been reported having neuronal defect on the frontal bone and was not surgically treated (Ayyappan et al. 1996). The present case differs from that, the Meningocoele was present on the occipital region and was treated successfully by surgical intervention. In most cases of Meningocoele reported in different animals, no neurological signs were observed but in present case the calf was having weak suckling reflex that improved gradually after surgery.

\section{Conclusion}

Meningocoele in buffalo calves can be identified by clinical examination and ultrasound examination and can be successfully treated by using elliptical incisional approach near base of swelling.

\section{Author Contributions}

SAM and AS planned the whole work. SAM and DR performed experimental work and HIA helped in write up and statistical analysis.

\section{References}

Ayhan A, Y Duygu, CD Ahmet (2013). Congenital giant occipital meningoencephalocele in a holstein calf fetus. Kafkas Univ Vet Fak Derg 19:1065-1069

Ayyappan S, S Balasubramanian, A Subramanian, P Dhanapalan (1996). Congenital Meningocoele in a buffalo calf - A Case report. Cheiron 25:162-163

William J, MS Simon, S Ayyappan, C Ramani, S Kumar (2011). Surgical management of cranial meningocoele in a calf. Tamil J Vet Anim Sci 7:164-166

Laiju M, M Philip, Ranjith, F Bastin, MC Sajesh (2012). Surgical repair of frontal meningocele in a kid. J Ind Vet Assoc 10:50-52

Leipold HW (1993). Congenital defects of cattle and sheep. Curr Vet Ther 1993:89-97

Maxie MG, S Youssef (2007). Malformations of the central nervous system. Pathol Domest Anim 1:317-321

Oliver JE, JR Duncan, IG Mayhew (1987). Laboratory examinations. In: Veterinary Neurology, pp: 57-64. Oliver JE, BF Hoerlein, IG Mayhew, WB Saunders (Eds.). Philadelphia, USA 